\title{
Potential applications of image-guided radiotherapy for radiation dose escalation in patients with early stage high-risk prostate cancer
}

\section{Nam P. Nguyen ${ }^{1}$, Rick Davis ${ }^{2}$, Satya R. Bose ${ }^{1}$, Suresh Dutta ${ }^{3}$, Vincent Vinh-Hung ${ }^{4}$, Alexander Chi $^{5}$, Juan Godinez ${ }^{6}$, Anand Desai ${ }^{7}$, William Woods ${ }^{8}$, Gabor Altdorfer ${ }^{9}$, Mark D'Andrea ${ }^{10}$, Ulf Karlsson ${ }^{11}$, Richard A. Vo ${ }^{12}$, Thomas Sroka ${ }^{13}$ and the International Geriatric Radiotherapy Group}

1 Department of Radiation Oncology, Howard University, Washington, DC, USA

2 Department of Radiation Oncology, Michael D. Wachtel Cancer Center, Oskosh, WI, USA

${ }^{3}$ Department of Radiation Oncology, Medicine and Radiation Oncology PA, San Antonio, TX, USA

${ }^{4}$ Department of Radiation Oncology, Martinique University Hospital, Martinique, France

${ }^{5}$ Department of Radiation Oncology, University of West Virginia, Morgantown, WV, USA

${ }^{6}$ Department of Radiation Oncology, Rochester Radiation Oncology Group, Rochester, NY, USA

7 Department of Radiation Oncology, Akron City Hospital, Akron, OH, USA

${ }^{8}$ Department of Radiation Oncology, Richard A. Henson Institute, Salisbury, ML, USA

${ }^{9}$ Department of Radiation Oncology, Camden Clark Cancer Center, Parkersburg, WV, USA

${ }^{10}$ Department of Radiation Oncology, University Cancer Centers, Houston, TX, USA

${ }^{11}$ Department of Radiation Oncology, Marshfield Clinic, Marshfield, WI, USA

12 University of Galveston School of Medicine, Galveston, TX, USA

${ }^{13}$ Department of Radiation Oncology, Geisel School of Medicine at Dartmouth, Dartmouth College, Hanover, NH, USA

Edited by:

John Varlotto, University of

Massachusetts Medical Center, USA

Reviewed by:

Joshua Silverman, New York

University Medical Center, USA

Wenyin Shi, Thomas Jefferson

University, USA

\section{*Correspondence}

Nam P. Nguyen, Department of

Radiation Oncology, Howard

University Hospital, 2401 Georgia

Avenue NW, Washington, DC 20060

USA

e-mail: namphong.nguyen@

yahoo.com
Patients with early stage high-risk prostate cancer (prostate specific antigen $>20$, Gleason score $>7$ ) are at high risk of recurrence following prostate cancer irradiation. Radiation dose escalation to the prostate may improve biochemical-free survival for these patients. However, high rectal and bladder dose with conventional three-dimensional conformal radiotherapy may lead to excessive gastrointestinal and genitourinary toxicity. Image-guided radiotherapy (IGRT), by virtue of combining the steep dose gradient of intensity-modulated radiotherapy and daily pretreatment imaging, may allow for radiation dose escalation and decreased treatment morbidity. Reduced treatment time is feasible with hypo-fractionated IGRT and it may improve patient quality of life.

Keywords: prostate cancer, high-risk, image-guided radiotherapy, hypofractionation

\section{INTRODUCTION}

Prostate cancer is currently detected at an early stage because of routine screening for prostate specific antigen (PSA) in elderly males (1). Patients with low-risk early stage prostate cancer (PSA $<10$, Gleason score $<5)$ demonstrate optimal results when treated with surgery or radiotherapy. However, in high-risk early stage prostate cancer patients (PSA $>20$, Gleason score $>7$ ), the current recommendation is androgen suppression therapy combined with radiotherapy because of potential for local recurrences and distant metastases (2). Increasing radiation dose to the prostate may improve local control and survival of these patients (3). However, normal organs adjacent to the prostate specifically the rectum, and bladder also receive a high radiation dose with dose escalation using the conventional three-dimensional conformal radiotherapy (3D-CRT) technique, which leads to a higher risk of complications (3). Thus, a radiotherapy technique that allows radiation dose escalation to the prostate while minimizing radiation to the rectum and bladder may improve the therapeutic ratio. Intensity-modulated radiotherapy (IMRT) has been introduced recently to decrease excessive radiation dose to the normal organs near the prostate cancer because of the steep dose gradient away from the target (4). Compared to 3D-CRT, IMRT may increase survival rates in patients with high-risk disease because of reduced rectal volume irradiated over $70 \mathrm{~Gy}$ and significantly decreased gastrointestinal (GI) toxicity, thus allowing radiation dose escalation to the tumor (5). However, in radiation dose escalation trials for prostate cancer, patients who had higher rectal doses during IMRT were still at an increased risk of long-term rectal complications (6). Inclusion of a large rectal volume in the IMRT planning treatment volume (PTV) may be required to avoid a marginal miss and therefore lead to excessive rectal irradiation. The introduction of image-guided radiotherapy (IGRT), which combines the normal tissue sparing effect of IMRT and daily imaging, has been proven to decrease further radiation dose to the normal organs without compromising local control in head and neck cancer (7-9). Thus, IGRT may allow for radiation dose escalation in patients with early stage high-risk prostate cancer and improve biochemical-free survival while reducing treatment toxicity. 


\section{TECHNIQUES OF PROSTATE CANCER RADIATION THERAPY DELIVERY WITH IGRT}

Currently, many systems are used for daily imaging and may be classified as invasive and non-invasive. In the invasive systems, metallic markers are implanted into the prostate as fiducial markers (FM) to guide radiation delivery. Usually, three seeds are implanted under ultrasound (US) guidance into the prostate before CT planning. Daily MV or kV CT are performed to align the seeds to the planning CT before each treatment. Alternatively, the seeds can be tracked in real time imaging with a robotic system (Cyberknife) or through electromagnetic waves emitted by the transponders (Calypso System), and allow accurate radiation delivery even though the prostate moves during treatment. In the non-invasive system, the prostate position before treatment can be detected either by US or by CT scan. The patient is shifted for set-up discrepancies and additional images are obtained to verify treatment accuracy. The US system is inexpensive, simple, and non-radiation-based, but is operator-dependent. The CT system provides either $\mathrm{kV}$ or MV imaging. Fan beam $\mathrm{kV}$ CT uses a diagnostic CT scan alongside the linear accelerator. Cone beam kV CT uses a gantry mounted $\mathrm{kV}$ source and a flat panel detector. A series of $\mathrm{kV} \mathrm{X}$-rays are taken when the gantry rotates and a 3D image is reconstructed. Image quality is superior with fan beam $\mathrm{kV} \mathrm{CT}$ compared to cone beam CT, but the couch needs to be displaced between imaging and treatment, which may lead to positioning error. In the MV CT system, the imaging is performed by the treatment beam that rotates around the patient while the couch moves (helical Tomotherapy).

Image quality is inferior with MV CT compared to kV CT, but there are no metal artifacts, which may be helpful if the patient has hip prosthesis. The latest technology for tumor imaging is based on magnetic resonance imaging (MRI), which involves a hybrid Cobalt linear accelerator and an MRI (ViewRay). This is a promising technology for prostate cancer IGRT, as MRI provides better imaging of the prostate gland compared to CT scans. Furthermore, MRI allows visualization of gross tumor volume (GTV) inside the prostate and may enable a higher radiation dose using the simultaneous integrated boost (SIB) technique.

\section{REDUCTION OF PROSTATE CANCER TREATMENT MORBIDITY ASSOCIATED WITH ACCURATE IMAGE GUIDANCE}

Preliminary evidence suggests that better visualization of the prostate during radiotherapy leads to improved patient quality of life (QOL) because of the increased accuracy of radiation delivery. In a study of 282 prostate cancer patients treated with 3D-CRT with $(n=154)$ and without image guidance $(n=128)$, proctitis severity was significantly reduced with image guidance (10). Patients who had image guidance underwent prostate FM placement and MRI imaging before radiotherapy planning to outline the target volume. Rectal and urinary dysfunction during radiotherapy was assessed with QOL questionnaires. Despite a higher tumor dose to the prostate, patients treated with image guidance experienced less diarrhea and rectal pain compared to the ones who did not undergo IGRT. During radiotherapy, the prostate position changes daily depending on bladder and rectal filling. Accurate target localizing with intra-prostate FM instead of bony landmark fusion leads to a decreased volume of bladder and rectum being irradiated to a high dose and therefore a reduction of acute morbidity. Gill et al. (11) reported significant reduction in severe urinary frequency, diarrhea, and fatigue in patients with prostate cancer who were treated with IGRT $(n=265)$ compared with patients not treated with IGRT $(n=26)$. Both groups were treated with IMRT using the same constraints and PTV margins. The prostate dose was higher for the group treated with IGRT (78 Gy) compared to those treated without IGRT (74 Gy). Thus, regardless of the radiotherapy technique, accurate localization of the prostate before treatment decreases treatment toxicity by eliminating the geographic miss of the prostate, which would lead to an excessive radiation dose to the adjacent non-involved normal structures. Other studies have corroborated the image guidance effects on sparing normal organs in patients with prostate cancer $(12,13)$.

\section{RADIATION DOSE ESCALATION FOR HIGH-RISK PROSTATE CANCER PATIENTS TREATED WITH IGRT AND CONVENTIONAL FRACTIONATION}

In patients with high-risk prostate cancer, long-term follow-up suggests that a radiation dose $\geq 80-81$ Gy to the tumor bed may be required for long-term biochemical control $(14,15)$. The effect of radiation dose escalation may be independent of hormonal therapy (15). Radiation doses up to 86.4 Gy were determined to be feasible with limited toxicity in prostate cancer patients treated with IMRT (16). In a study of 1,002 prostate cancer patients treated to 86.4 Gy with IMRT, late grade $3 \mathrm{GI}$ and genitourinary (GU) toxicities were reported ( 0.7 and $2.2 \%$, respectively). However, acute grade 3-4 toxicities were not reported in the study. Thus, IGRT may allow for radiation dose escalation and further reduction of normal tissue toxicity by combining IMRT and daily imaging. Indeed, preliminary evidence suggests that IGRT as a safe radiotherapy technique for radiation dose escalation in patients with prostate cancer. Takeda et al. (17) reported no acute grade 3-4 toxicities in 141 patients with intermediate or high-risk localized prostate cancer when the radiation dose was increased from $76 \mathrm{~Gy}$ $(n=13)$ to $80 \mathrm{~Gy}(n=128)$. Only two patients developed longterm grade 3 toxicities. Kok et al. (18) compared late toxicities among 311 patients treated with IMRT for prostate cancer without image guidance ( $74 \mathrm{~Gy}$ ) and with image guidance (78 Gy). Despite a higher radiation dose in this study, late GI toxicities were significantly reduced in patients with image guidance. In a similar study comparing IGRT (78 Gy) and 3D-CRT (76 Gy) for highrisk prostate cancer, late GI and GU toxicities were significantly decreased for patients treated with IGRT (19).

\section{RADIATION DOSE ESCALATION FOR HIGH-RISK PROSTATE CANCER PATIENTS TREATED WITH IGRT AND HYPOFRACTIONATION}

Prostate cancer cells are characterized by a low $\alpha / \beta$ ratio ranging from 0.8 to $2.2 \mathrm{~Gy}$, suggesting that delivering a radiation dose higher than the conventional fractionation of 1.8-2 Gy/day may be more effective for cancer cell killing. On the opposite side is the risk of normal tissue injury associated with high dose hypofractionation. However, if the volume of rectal and bladder tissue exposed to a high radiation dose can be reduced with high precision radiation delivery, hypofractionation may be an 
ideal radiation technique to reduce treatment time while potentially improving the biochemical control in patients with high-risk prostate cancer. Jerekzek-Fossa et al. (20) compared the acute toxicity of 179 prostate cancer patients treated with IGRT [70.2 Gy in $2.7 \mathrm{~Gy} /$ fraction (84.2 Gy dose equivalent in $2 \mathrm{~Gy} /$ fraction)] and 174 patients treated with 3D-CRT ( $80 \mathrm{~Gy}$ in 2 Gy fraction). There was no significant difference in toxicity between the two groups of patients. In a follow-up study, QOL of the patients treated with hypo-fractionated IGRT was not significantly affected longterm, thus illustrating that IGRT may be beneficial in patients with high-risk prostate cancer (21). A similar radiation dose escalation study was performed in 48 prostate cancer patients using regimens of $68.04 \mathrm{~Gy}$ at $2.52 \mathrm{~Gy} /$ fraction $(n=32), 70 \mathrm{~Gy}$ at $2.5 \mathrm{~Gy} /$ fraction $(n=5)$, and $70.2 \mathrm{~Gy}$ at $2.6 \mathrm{~Gy} /$ fraction. No patients developed grade 3-4 late toxicities (22). The safety of IGRT for hypofractionation was also corroborated in another study where patients with high-risk prostate cancer were treated up to $74.2 \mathrm{~Gy}$ in $2.65 \mathrm{~Gy} /$ fraction with the SIB technique. Only 1 out of 70 patients developed an acute grade 3 rectal reaction (23). A preliminary report from a randomized study comparing high dose hypofractionation to conventional fractionation with IGRT suggests that hypo-fractionation may allow for a higher radiobiologic dose without increasing treatment toxicity for high-risk prostate cancer patients. Patients $(n=124)$ were recruited and treated to $76 \mathrm{~Gy}$ in $2 \mathrm{~Gy} /$ fraction $(n=57)$ and $63 \mathrm{~Gy}$ in $3.15 \mathrm{~Gy} /$ fraction $(n=67)$ equivalent to $84 \mathrm{~Gy}$ in $2 \mathrm{~Gy} /$ fraction to the prostate with the SIB technique (24). There was no significant difference in acute toxicities between the two arms suggesting that IGRT may confer effective normal tissue sparing but long-term follow-up is needed as complications may develop later.

The extreme hypo-fractionation scheme for high-risk prostate cancer involves continuous tracking of the prostate with two orthogonal X-ray imagers that allow a tight PTV margin posteriorly $(3 \mathrm{~mm})$ while multiple non-coplanar beams improve the plan conformity compared to IMRT (Cyberknife) (25). Total treatment time can be reduced to 1 week instead of the conventional $8-9$ weeks of treatment as the volume of rectum and bladder exposed to high radiation dose can be minimized. In addition, if treatment toxicity can be reduced, a high dose to the prostate may be feasible to improve local control. Oliai et al. (26) reported the acute toxicity and long-term complications of 70 patients with low- to high-risk prostate cancer treated with radiation dose escalation by Cyberknife (CK) ranging from $35 \mathrm{~Gy}$ in $7 \mathrm{~Gy} /$ fraction $(n=5), 36.25 \mathrm{~Gy}$ in $7.25 \mathrm{~Gy} /$ fraction $(n=36)$, and $37.5 \mathrm{~Gy}$ in $7.5 \mathrm{~Gy} /$ fraction $(n=29)$. Acute and late grade $3 \mathrm{GU}$ toxicities were 4 and 3\%, respectively. None of the patients experienced grade 3-4 toxicities at a median follow-up of 31 months. Katz et al. (27) also corroborated the low toxicity of CK for prostate cancer. Among 304 patients with low $(n=211)$, intermediate $(n=81)$, and high-risk $(n=12)$ prostate cancer treated with $\mathrm{CK}$ to $35 \mathrm{~Gy}$ in $7 \mathrm{~Gy} /$ fraction $(n=50)$ and $36.25 \mathrm{~Gy}$ in $7.25 \mathrm{~Gy} /$ fraction $(n=254)$, none of the patients developed acute grade $3-4$ toxicity. At a median followup of 60 months, only $2 \%$ of the patients developed long-term grade $3 \mathrm{GU}$ toxicity. A follow-up study suggested that prostate cancer patients treated with this fractionation on CK had QOL similar to that observed in conventional fractionation (28). Even though most patients treated with CK hypo-fractionation had low to intermediate risk prostate cancer, late grade $3 \mathrm{GI}$ and GU toxicities ranged from 0 to $3 \%$, which confirmed the safety of CK for radiation dose escalation (29-34). The high radiobiologic equivalent dose of $92 \mathrm{~Gy}$ (corresponding to $35 \mathrm{~Gy}$ in $7 \mathrm{~Gy} /$ fraction with an $\alpha / \beta$ ratio of 1.5 ) or higher with hypo-fractionated CK suggests that this radiotherapy technique may be potentially effective for high-risk prostate cancer. However, this hypothesis will need to be tested in future prospective trials. It is encouraging that in a pooled analysis of patients with prostate cancer treated with hypo-fractionated CK, a 5-year PSA relapse-free survival of $81 \%$ was suggested for high-risk patients.

\section{ROLE OF BRACHYTHERAPY IN RADIATION DOSE ESCALATION IN PATIENTS WITH HIGH-RISK PROSTATE CANCER}

Brachytherapy may be the ideal modality of radiation dose escalation for prostate cancer either alone or as a boost. The radioactive seeds or high dose rate (HDR) brachytherapy catheters are inserted inside the prostate, thus prostate motion is not an issue for brachytherapy compared to external beam radiation. In addition, the radiation dose decreases proportionally to the square of the distance away from the radioactive sources and allows significant sparing of the rectum and bladder. Because of the risk of extracapsular extension of the tumor, brachytherapy is frequently given as a boost following external beam radiation, but brachytherapy without external beam radiation has been reported with excellent local control and survival in selected studies when combined with androgen deprivation therapy (35-37). A higher dose to the prostate ranging from 10,000 to 12,000 cGy may be achieved as a boost after external beam radiation with low dose rate (LDR) brachytherapy $(38,39)$. As a result, long-term biochemical-free survival has been observed with LDR brachytherapy boost for high-risk prostate cancer (40). Brachytherapy with HDR begins to play a prominent role in the management of high-risk prostate cancer because of the technical issues associated with LDR permanent seeds implant: discrepancy between planned and actual seeds distribution, inability to correct seeds position or to optimize the dose delivered once the seeds are in place, which may be related to the radiation oncologist technical skills. The HDR catheters are relatively easy to visualize with US and may be safely implanted outside the prostate capsule and into the seminal vesicles without the risk of seeds migration. Uncertainty over target dose associated with prostate volume changes, which occurs following LDR seeds implant is not an issue with HDR brachytherapy. Perhaps the most important advantage of HDR over LDR brachytherapy is the real time dose modulation, which provides immediate feedback to the physician and physicist for optimal catheter distribution and dwell time. Preliminary results of HDR monotherapy or combined with external beam radiotherapy were very encouraging with excellent biochemical-free survival and acceptable toxicity (35-37, 41, 42). Dose escalation with HDR boost after external beam radiotherapy was feasible and was reported to be associated with a higher biochemical-free survival in high-risk prostate cancer patients $(43,44)$. As most studies reported 3D-CRT with HDR brachytherapy, it would be interesting to combine IGRT and HDR brachytherapy for high-risk prostate cancer to decrease longterm complications in future prospective studies. Nevertheless, 
brachytherapy is an invasive procedure with its complications and may not be indicated for all patients. The optimal radiation dose for disease control in high-risk prostate cancer has not been elucidated when combined with androgen deprivation therapy and needs to be investigated in future clinical trials.

\section{CURRENT CONTROVERSIES IN THE MANAGEMENT OF HIGH-RISK PROSTATE CANCER}

\section{ROLE OF PELVIC RADIOTHERAPY IN THE TREATMENT OF HIGH RISK OF} PROSTATE CANCER

As high-risk prostate cancer patients may have occult pelvic lymph nodes metastases that are not detected with current diagnostic technologies, pelvic lymph nodes irradiation may improve locoregional control and survival. However, these patients also received androgen deprivation therapy that may affect micrometastases. On the other hand, treating the prostate and seminal vesicles only allows radiation dose escalation without the toxicity of pelvic irradiation. Radiation dose escalation from 64 to 74 Gy to a local field with 3D-CRT and neoadjuvant androgen deprivation has been reported to improve biochemical-free survival in a randomized study (45). Using the Roach formula to estimate the risk of pelvic lymph nodes metastases, a matched-pair analysis did not report the benefit of adding pelvic radiotherapy in patients at high risk ( $>15 \%$ ) of lymph nodes metastases (46). Two randomized studies also corroborated the lack of survival benefit when the pelvis was radiated compared to irradiation of the prostatic bed only (47, 48). As an illustration, excellent local control and survival were observed in studies where HDR brachytherapy to the prostate were combined with hormonal therapy without pelvic irradiation (35$37,49)$. The rate of distant metastases or pelvic failures did not increase in those studies. Thus, pelvic irradiation may not be necessary for high-risk prostate cancer when combined with androgen deprivation therapy and may increase treatment toxicity because of the increased volume of normal tissues in the radiation fields.

\section{PROSTATE MOTION AND OPTIMAL PTV FOR IGRT}

Prostate motion depends on rectal and bladder filling. In the supine position for treatment, prostate position is less affected by bladder filling because of bladder extension anteriorly. However, in the prone position, pressure on the bladder may push the prostate posteriorly and the prostate position is affected by the patient breathing pattern (50). Prostate motion ranged from 1.5 to $3.7 \mathrm{~mm}, 0.7$ to $1.9 \mathrm{~mm}$, and 1.4 to $3.6 \mathrm{~mm}$ in the antero-posterior (AP), left-to-right (LR), and superior-inferior (SI) dimension, respectively (51-55). The magnitude of prostate motion also depends on the individual patient. Choice of a PTV also depends on whether the institution includes pelvic lymph node irradiation or not as it would be difficult to tract the motion of two independent systems. In that sense, radiation dose escalation would be technically easier without pelvic irradiation. PTV margins for the lymph nodes may need to be enlarged to avoid under dosing the pelvic lymph nodes if the set up needs to change because of prostate motion secondary to rectal filling. The choice of the PTV margins also depends on the prostate tracking system used by the institution, either with FM or electromagnetic transponders (invasive method), or with soft tissue fusion based on CBCT or MVCT. For the non-invasive method, once an optimum PTV has been selected by the institution, adaptive therapy performed for the first week or two of treatment based on observed prostate motion on an individual patient may allow the clinician to reduce the PTV for example if the established PTV may be too generous. These efforts may reduce interfraction motion but will not reduce intrafraction motion that occurs during treatment. Unless the institution uses an online tracking system for treatment delivery such as the robotic CK, PTV margins should take into account intrafraction motion, which may be dependent on treatment time. The use of an endorectal balloon may decrease intrafraction prostate motion and may reduce further rectal dose by pushing the posterior rectal wall away from the high dose area (56). Another factor to take into consideration is the deformation of the prostate, which may be related to peristalsis, degree of pelvic musculature contraction, and breathing pattern. Any prospective trial on radiation dose escalation should take into consideration the degree prostate deformation during treatment as under dosing of the prostate may occur in patients with a large degree of prostate deformation (more than $10 \%$ of prostate volume) (57).

In summary, PTV margins should be determined by the type of IGRT image tracking and radiation treatment delivery. For example, published recommended LR, AP, and SI margins ranged from $3.6,3.7$, and $3.7 \mathrm{~mm}$ and $2.46,2.28$, and $2.56 \mathrm{~mm}$ for FM and CBCT, respectively $(58,59)$.

\section{DOSE PRESCRIPTION COMPARISON AMONG INSTITUTIONS USING PROSTATE IGRT}

Currently, there is no standard recommendation on how to prescribe radiation dose for patients undergoing prostate IGRT. Each institution set up a specific protocol making dose comparison difficult among various institutions to assess long-term local control, and complications. In addition, there were different dose schedule fractionation, and various PTV margins based the technology used for image tracking. As an illustration, Norkus et al. (24) reported the following protocol in a randomized study of dose escalation using hypofractionation and CBCT for image guidance. The prostate PTV was treated to a total dose of $76 \mathrm{~Gy}$ at $2 \mathrm{~Gy} /$ fraction and $63 \mathrm{~Gy}$ at $3.15 \mathrm{~Gy} /$ fraction, respectively, with a PTV margin of $10 \mathrm{~mm}$ except posteriory $(7 \mathrm{~mm})$. The dose was optimized so that $95-108 \%$ of the PTV received the prescribed dose. On the other hand, Takeda et al. (17) treated the prostate PTV to a total dose of 80 Gy in 2 Gy/fraction using FM with a PTV margin of $5 \mathrm{~mm}$ except posteriorly $(3 \mathrm{~mm})$. The dose was prescribed to cover $95 \%$ of the target volume. At another institution, even though FM was used for image guidance, the prostate PTV margin was $10 \mathrm{~mm}$ except posteriorly $(6 \mathrm{~mm})$. The prescribed dose was $86.4 \mathrm{~Gy}$ to a maximum isodose encompassing the PTV (60). As the preliminary results from these institutions are excellent for local control with acceptable toxicity, it would be very difficult to set up a standard recommendation for PTV margins and dose.

\section{FUTURE DIRECTIONS OF IMAGE-GUIDED RADIOTHERAPY FOR RADIATION DOSE ESCALATION IN PATIENTS WITH HIGH-RISK PROSTATE CANCER}

Patient with high-risk prostate cancer often have a heterogeneous tumor distribution within the prostate with areas of concentrated cancer cells responsible for disease recurrence following 
radiotherapy (61). These intra-prostatic tumor nodules may require a higher dose to achieve local control. The conventional radiotherapy technique with IMRT or IGRT for prostate cancer consists of a homogeneous radiation dose distribution within the prostate. Thus, previous studies of radiation dose escalation increased the total dose to the prostate, which may account for the risk of late GI and GU complications. New imaging techniques such as diffusion-weighted (DW), MRI, magnetic resonance spectroscopy (MRS), and positron emission tomography (PET)-CT are more accurate for detection of these intra-prostatic tumor nodules and may allow for radiation dose escalation within the prostate (62-64). Dosimetric studies suggest that radiation dose escalation for intra-prostatic tumors nodules with IGRT is feasible and may allow significant reduction of the rectal dose (65). In a clinical study of 118 patients with prostate cancer, the GTV defined by MRI or MRS was treated to $80-81$ Gy while the prostate dose was limited to $78 \mathrm{~Gy}$ with IMRT. No patients developed grade 3-4 GI toxicity (66). Thus, IGRT may be a promising technique for radiation dose escalation on intra-prostatic nodules as significant rectal toxicity has been observed in patients who had hypo-fractionated IGRT up to $50 \mathrm{~Gy}$ in $10 \mathrm{~Gy} /$ fraction (67).

\section{CONCLUSION}

Image-guided radiotherapy is a promising technique to reduce treatment toxicity in patients with early stage high-risk prostate carcinoma and may improve biochemical-free survival associated with radiation dose escalation. Reduced treatment time with hypofractionated IGRT may improve patient QOL as they will have more time to spend with their family. Future clinical trials focused on improving tumor imaging with MRI, MRS, and PET-CT to reduce long-term complications associated with high dose prostate irradiation are warranted.

\section{REFERENCES}

1. DeSantis CE, Lin CC, Mariotto AB, Siegel RL, Stein KD, Kramer JL, et al. Cancer treatment and survivorship statistics, 2014. CA Cancer J Clin (2014) 64(4):252-71. doi:10.3322/caac. 21235

2. Nguyen PL, Chen MH, Beard CJ, Suh WW, Renshaw AA, Lofredo AA, et al. Radiation with or without 6 months of androgen suppression therapy in intermediate and high-risk clinically localized prostate cancer: a postrandomization analysis by subgroup. Int J Radiat Oncol Biol Phys (2010) 77:1046-52. doi:10.1016/j.ijrobp.2009.06.038

3. Kuban DA, Tucker SL, Dong L, Starkschall G, Huang EH, Cheung MR, et al. Long-term results of the M. D. Anderson dose-escalation trial for prostate cancer. Int J Radiat Oncol Biol Phys (2008) 70:67-74. doi:10.1016/j.ijrobp.2007.06.054

4. Michalski JM, Yan Y, Watkins-Bruner D, Bosch WR, Winter K, Galvin JM, et al. Preliminary toxicity analysis of 3-dimensional conformal radiation therapy versus intensity-modulated radiation therapy on the high dose arm of the Radiation Therapy Oncology Group 0126 prostate cancer trial. Int J Radiat Oncol Biol Phys (2013) 87:932-8. doi:10.1016/j.ijrobp.2013.07.041

5. Gandaglia G, Karakiewicz PI, Briganti A, Trinh QD, Schiffmann J, Tian Z, et al. Intensity-modulated radiation therapy leads to survival benefit only in patients with high-risk prostate cancer: a population-based study. Ann Oncol (2014) 25:979-86. doi:10.1093/annonc/mdu087

6. Hoffman KE, Voong KR, Pugh TJ, Skinner H, Levy LB, Takiar V, et al. Risk of late toxicity in men receiving dose-escalated hypofractionated intensity modulated prostate radiation therapy: results from a randomized trial. Int J Radiat Oncol Biol Phys (2014) 88:1074-84. doi:10.1016/j.ijrobp.2014.01.015

7. Nguyen NP, Ceizyk M, Vos P, Vinh-Hung V, Davis R, Desai A, et al. Effectiveness of image-guided radiotherapy for laryngeal sparing in head and neck cancer. Oral Oncol (2010) 46:283-6. doi:10.1016/j.oraloncology.2010.01.010
8. Nguyen NP, Smith-Raymond L, Vinh-Hung V, Vos P, Davis R, Desai A, et al. Feasibility of tomotherapy-based image-guided radiotherapy to reduce aspiration risk in patients with non-laryngeal and non-hypopharyngeal head and neck cancer. PLoS One (2013) 3:e56290. doi:10.1371/journal.pone.0056290

9. Nguyen NP, Ceizyk M, Vos P, Betz M, Chi A, Almeida F, et al. Feasibility of tomotherapy-based image-guided radiotherapy for locally advanced oropharyngeal cancer. PLoS One (2013) 8:e60268. doi:10.1371/journal.pone.0060268

10. Singh J, Greer PB, White MA, Parker J, Patterson J, Tang CI, et al. Treatment related morbidity in prostate cancer: a comparison of 3-dimensional conformal radiation therapy with and without image guidance using implanted fiducial markers. Int J Radiat Oncol Biol Phys (2013) 85:1018-23. doi:10.1016/j.ijrobp. 2012.07.2376

11. Gill S, Thomas J, Fox C, Kron T, Rolfo A, Leahy M, et al. Acute toxicity in prostate cancer treated with and without image-guided radiotherapy. Radiat Oncol (2011) 6:145. doi:10.1186/1748-717X-6-145

12. Lipps IM, Dehnad H, Van Gils CH, Kruger B, Arto E, Van der Heide UA, et al. High-dose intensity-modulated radiotherapy for prostate cancer using fiducial marker-based position verification: acute and late toxicity in 331 patients. Radiat Oncol (2008) 3:35. doi:10.1186/1748-717X-3-15

13. Soete G, Verellen D, Michielsen D, Rappe B, Keuppen F, Storme G. Image-guided conformal arc therapy for prostate cancer: early side-effects. Int J Radiat Oncol Biol Phys (2006) 66:S141-4. doi:10.1016/j.ijrobp.2006.05.077

14. Zelefsky MJ, Pei X, Chou JF, Schechter M, Kollmeier M, Cox B, et al. Dose escalation for prostate cancer radiotherapy: predictors of long-term biochemical tumor control and distant metastases-free survival outcomes. Eur Urol (2011) 60:1133-9. doi:10.1016/j.eururo.2011.08.029

15. Pahlajani N, Ruth KJ, Buyyounouski MK, Chen DYT, Horwitz EM, Hanks GE, et al. Radiotherapy doses of 80 Gy or higher are associated with lower mortality in men with Gleason score 8-10 prostate cancer. Int J Radiat Oncol Biol Phys (2012) 82:1949-56. doi:10.1016/j.ijrobp.2011.04.005

16. Spratt DE, Pei X, Yamada J, Kollmeier MA, Cox B, Zelefsky MJ. Long-term survival and toxicity in patients treated with high dose intensity-modulated radiation therapy for prostate cancer. Int J Radiat Oncol Biol Phys (2013) 85:686-92. doi:10.1016/j.ijrobp.2012.05.023

17. Takeda K, Takai Y, Narazaki K, Mitsuya M, Umezawa R, Kadoya N, et al. Treatment outcome of high-dose image-guided intensity-modulated radiotherapy using intra-prostatic fiducial markers for localized prostate cancer at a single institute in Japan. Radiat Oncol (2012) 7:105. doi:10.1186/1748-717X-7-105

18. Kok D, Gill S, Bressel M, Byrne K, Kron T, Fox C, et al. Late toxicity and biochemical control in 554 prostate cancer patients treated with and without dose escalated image guided radiotherapy. Radiother Oncol (2013) 107:140-6. doi:10.1016/j.radonc.2013.04.007

19. Sveistrup J, Rosenschold PM, Deasy JO, Oh JH, Pommer T, Peterson PM, et al. Improvement in toxicity in high risk prostate cancer patients treated with image-guided intensity-modulated radiation therapy compared to $3 \mathrm{D}$ conformal radiotherapy without daily image guidance. Radiat Oncol (2014) 9:44. doi:10.1186/1748-717X-9-44

20. Jereczek-Fossa BA, Zerini D, Fodor C, Santoro L, Cambria R, Garibaldi C, et al. Acute toxicity of image-guided hypofractionated radiotherapy for prostate cancer: non-randomized comparison with conventional fractionation. Urol Oncol (2011) 29:523-32. doi:10.1016/j.urolonc.2009.10.004

21. Jereczek-Fossa BA, Santoro L, Zerini D, Fodor C, Vischioni B, Dispinzieri M, et al. Image-guided hypofractionated radiotherapy and quality of life for localized prostate cancer: prospective longitudinal study in 337 patients. J Urol (2013) 189:2099-103. doi:10.1016/j.juro.2013.01.005

22. Guerra JLL, Isa N, Matute R, Russo M, Puebla F, Kim MM, et al. Hypofractionated helical tomotherapy using 2.5-2.6 Gy daily fractions for localized prostate cancer. Clin Transl Oncol (2013) 15:271-7. doi:10.1007/s12094-012-0907-y

23. Alongi F, Fogliata A, Navarria P, Tozzi A, Mancosu P, Lobefalo F, et al. Moderate hypofractionation and simultaneous integrated boost with volumetric modulated arc therapy (RapidArc) for prostate cancer. Report of feasibility and acute toxicity. Strahlenther Onkol (2012) 188:990-6. doi:10.1007/s00066-012-0171-7

24. Norkus D, Karkhelyte A, Engels B, Versmessen H, Griskevicius R, De Ridder $\mathrm{M}$, et al. A randomized hypofractionation dose escalation trial for high risk prostate cancer patients: interim analysis of acute toxicity and quality of life in 124 patients. Radiat Oncol (2013) 8:206. doi:10.1186/1748-717X-8-206

25. Hossain S, Xia P, Huang K, Descovich M, Chuang C, Gottschalk AR, et al. Dose gradient near target-normal structure interface for nonisocentric cyberknife 
and isocentric intensity-modulated body radiotherapy for prostate cancer. Int $J$ Radiat Oncol Biol Phys (2010) 78:58-63. doi:10.1016/j.ijrobp.2009.07.1752

26. Oliai C, Lanciano R, Sprandio B, Yang J, Lamond J, Arrigo S, et al. Stereotactic body radiation therapy for the primary treatment of localized prostate cancer. J Radiat Oncol (2013) 2:63-70. doi:10.1007/s13566-012-0067-2

27. Katz AJ, Santoro M, Diblasio F, Ashley R. Stereotactic body radiotherapy for localized prostate cancer: disease control and quality of life at 6 years. Radiat Oncol (2013) 8:118. doi:10.1186/1748-717X-8-118

28. Bhattasali O, Chen LN, Woo J, Park J, Kim JS, Moures R, et al. Patient-reported outcomes following stereoractic body radiation therapy for clinically localized prostate cancer. Radiat Oncol (2014) 9:52. doi:10.1186/1748-717X-9-52

29. King CR, Brooks JD, Gill H, Presti JC Jr. Long-term outcomes from a prospective trial of stereotactic body radiotherapy for low risk prostate cancer. Int J Radiat Oncol Biol Phys (2012) 82:877-82. doi:10.1016/j.ijrobp.2010.11.054

30. McBride SM, Wong DS, Dombrowski JJ, Harkins B, Tapella P, Hanscom HN, et al. Hypofractionated stereotactic body radiotherapy in low-risk prostate adenocarcinoma: preliminary results of a multi-institutional phase I feasibility trial. Cancer (2012) 118:3681-90. doi:10.1002/cncr.26699

31. Bolzicco G, Favretto MS, Satariano N, Scremin E, Tambone C, Tasca A. A single center study of 100 consecutive patients with localized prostate cancer treated with stereotactic body radiotherapy. BMC Urol (2013) 13:49. doi:10.1186/1471-2490-13-49

32. Ju AW, Wang H, Oermann EK, Sherer BA, Uhm H, Chen VJ, et al. Hypofractionated stereotactic body radiation therapy as monotherapy for intermediate-risk prostate cancer. Radiother Oncol (2013) 8:30. doi:10.1186/1748-717X-8-30

33. Lee YH, Son SH, Yoon SC, Yu M, Choi BQ, Kim YS, et al. Stereotactic body radiotherapy for prostate cancer: a preliminary report. Asia Pac J Clin Oncol (2014) 10:e46-53. doi:10.1111/j.1743-7563.2012.01589.x

34. Kang JK, Cho CK, Choi CW, Yoo S, Kim MS, Yang K, et al. Image-guided stereotactic body radiation therapy for localized prostate cancer. Tumori (2011) 97:43-8. doi:10.1700/611.7137

35. Yoshioka Y, Konishi K, Sumida I, Takahashi Y, Isohashi F, Ogata H, et al. Monotherapeutic high-dose rate brachytherapy for prostate cancer: five-year results of an extreme fractionation regimen with $54 \mathrm{~Gy}$ in nine fractions. Int J Radiat Oncol Biol Phys (2011) 80:469-75. doi:10.1016/j.ijrobp.2010.02.013

36. Zamboglou N, Tselis N, Baltas D, Buhleir T, Martin T, Milickovis N, et al. High dose rate interstitial brachytherapy as monotherapy for clinically localized prostate cancer: treatment evolution and mature results. Int J Radiat Oncol Biol Phys (2013) 85:672-8. doi:10.1016/j.ijrobp.2012.07.004

37. Yoshida K, Yamazaki H, Takenada T, Kotsuma T, Yoshida M, Masui K, et al. High dose rate interstitial brachytherapy in combination with androgen deprivation therapy for prostate cancer. Strahlenther Oncol (2014) 190:1015-20. doi:10.1007/s00066-014-0675-4

38. Strom TJ, Hutchinson SZ, Shrinath K, Cruz AA, Figura NB, Nethers K, et al. External beam radiation therapy and a low dose rate brachytherapy boost without or with androgen deprivation therapy for prostate cancer. Int Braz J Urol (2014) 40:474-83. doi:10.1590/S1677-5538.IBJU.2014.04.05

39. Ohashi T, Yorozu A, Saito S, Momma T, Nishiyama T, Yamashita S, et al. Combined brachytherapy and external beam radiotherapy without androgen deprivation therapy for high risk prostate cancer. Radiat Oncol (2014) 9:13. doi:10.1186/1748-717X-9-13

40. Stone NN, Stock RG. 15-year cause specific and all cause specific survival following brachytherapy for prostate cancer. Negative impact of long-term hormonal therapy. J Urol (2014) 192:754-9. doi:10.1016/j.juro.2014.03.094

41. Wahlgren T, Nilsson S, Ryberg M, Lennernas B, Brandberg Y. Combined curative radiotherapy including HDR brachytherapy and androgen deprivation in localized prostate cancer: a prospective assessment of acute and late treatment toxicity. Acta Oncol (2005) 44:633-43. doi:10.1080/02841860510029716

42. Valero J, Cambeiro M, Galan C, Teijeira M, Romero P, Zudaire J, et al. Phase II trial of radiation dose escalation with conformal external beam radiotherapy and high dose rate brachytherapy combined with long-term androgen suppression in unfavorable prostate cancer: feasibility report. Int J Radiat Oncol Biol Phys (2010) 76:386-92. doi:10.1016/j.ijrobp.2009.01.059

43. Ares C, PopowskiY, Pampallona S, Nouet P, Dipasquale P, Bieri S, et al. Hypofractionated boost with high dose rate brachytherapy and open magnetic resonance imaging-guided implants for locally aggressive prostate cancer: a sequentially dose escalation pilot study. Int J Radiat Oncol Biol Phys (2009) 75:656-63. doi:10.1016/j.ijrobp.2008.11.023
44. Martinez AA, Gonzalez J, Ye H, Ghilezan M, Shetty S, Kernen K, et al. Dose escalation improves cancer-related events at 10 years for intermediate and high risk prostate cancer patients treated with hypofractionated high dose rate boost and external beam radiotherapy. Int J Radiat Oncol Biol Phys (2011) 79:363-70. doi:10.1016/j.ijrobp.2009.10.035

45. Dearnaley DP, Jovic G, Syndikus A, Khoo V, Cowan RA, Graham JD, et al. Escalated dose versus control dose conformal radiotherapy for prostate cancer: longterm results from the MRC RT01 randomized controlled trial. Lancet Oncol (2014) 15:464-73. doi:10.1016/S1470-2045(14)70040-3

46. Vargas CE, Demanes J, Boike TP, Barnaba MC, Skoolisariyaporn P, Schour L, et al. Matched pair analysis of prostate cancer patients with a high risk of positive pelvic lymph nodes treated with and without pelvic RT and high dose radiation using high dose rate brachytherapy. Am J Clin Oncol (2006) 29:451-7. doi:10.1097/01.coc.0000221304.74360.8c

47. Pommier P, Chabaud S, Lagrange JL, Richaud P, Lesaunier F, Le Prise E, et al. Is there a role for pelvic irradiation in localized prostate adenocarcinoma. J Clin Oncol (2007) 25:5366-73. doi:10.1200/JCO.2006.10.5171

48. Asbell SO, Krall JM, Pipelich MV, Baerwald H, Sause WT, Hanks GE, et al. Elective pelvic irradiation in stage A2, B carcinoma of the prostate: analysis of RTOG 77-06. Int J Radiat Oncol Biol Phys (1988) 15:1307-16. doi:10.1016/03603016(88)90225-8

49. Hoskin P, Rojas A, Ostler P, Hughes R, Alonzi R, Lowe G, et al. High dose rate brachytherapy with two or three fractions as monotherapy in the treatment of locally advanced prostate cancer. Radiother Oncol (2014) 112:63-7. doi:10.1016/j.radonc.2014.06.007

50. Malone S, Crook JM, Kendal WS, Szanto J. Respiratory-induced prostate motion: quantification and characterization. Int J Radiat Oncol Biol Phys (2000) 48:105-9. doi:10.1016/S0360-3016(00)00603-9

51. Rudat V, Schraube P, Oetzel D, Zierhut D, Flentje M, Wannenmacher M. Combined error of patient positioning variability and prostate motion uncertainty in 3D conformal radiotherapy of localized prostate cancer. Int J Radiat Oncol Biol Phys (1996) 35:1027-34. doi:10.1016/0360-3016(96)00204-0

52. Althof VG, Hoekstra CJ, te Loo HJ. Variation in prostate position relative to adjacent bony anatomy. Int J Radiat Oncol Biol Phys (1996) 34:709-15. doi:10.1016/0360-3016(95)02162-0

53. Nederveen AJ, van der Heide UA, Dehnah H, van Morselaar RJ, Hofman P, Lagendikj JJ. Measurements and clinical consequences of prostate motion during a radiotherapy fraction. Int J Radiat Oncol Biol Phys (2002) 53:206-14. doi:10.1016/S0360-3016(01)02823-1

54. Antolak JA, Rosen LL, Childress CH, Zagard GK, Pollack A. Prostate target volume variations during a course of radiotherapy. Int J Radiat Oncol Biol Phys (1998) 42:661-72. doi:10.1016/S0360-3016(98)00248-X

55. Hanley J, Lumley MA, Mageras GS, Sun J, Zelefsky MJ, Leibel SA, et al. Measurement of patient positioning errors in three-dimensional conformal radiotherapy of prostate. Int J Radiat Oncol Biol Phys (1997) 37:435-44. doi:10.1016/S0360-3016(96)00526-3

56. Smeenk RJ, Louwe RJW, Langen KJ, Shah AP, Kupelian AP, van Lin E, et al. An endorectal balloon reduces intrafraction prostate motion during radiotherapy. Int J Radiat Oncol Biol Phys (2012) 83:661-9. doi:10.1016/j.ijrobp. 2011.07.028

57. Mayyas E, Kim J, Kumar S, Liu C, Wen N, Movsas B, et al. A novel approach for evaluation of prostate deformation and associated dosimetric implications in IGRT of the prostate. Med Phys (2014) 41:091709. doi:10.1118/1.4893196

58. Skarsgard D, Cadman P, El-Gayed A, Pearcey R, Tai P, Pervez N, et al. Planning target volume margins for prostate radiotherapy using daily electronic portal imaging and implanted fiducial markers. Radiat Oncol (2010) 5:52. doi:10.1186/1748-717X-5-52

59. Tanyi JA, He T, Summers PA, Mburu JA, Kato CM, Rhodes SM, et al. Assessment of planning target volume margins for intensity-modulated radiotherapy of the prostate gland: role of daily inter- and intra-fraction motion. Int J Radiat Oncol Biol Phys (2010) 78:1579-85. doi:10.1016/j.ijrobp.2010.02.001

60. Zelefsky MJ, Kollmeier M, Cox B, Fidaleo A, Sperling D, Pei X, et al. Improved clinical outcomes with high dose image-guided radiotherapy compared with non-IGRT for the treatment of clinically localized prostate cancer. Int J Radiat Oncol Biol Phys (2012) 84:125-9. doi:10.1016/j.ijrobp.2011.11.047

61. Hong SK, Eastham JA, Fine SW. Localization of higher grade tumor foci in potential candidates for active surveillance who opt for radical prostatectomy. Prostate Int (2013) 1:152-7. doi:10.12954/PI.13029 
62. Styles C, Ferris N, Mitchell C, Murphy D, Frydenberg M, Mills J, et al. Multiparametric 3T MRI in the evaluation of intraglandular prostate cancer: correlation with histopathology. J Med Imaging Radiat Oncol (2014) 58(4):439-48. doi:10.1111/1754-9485.12189

63. Anwar M, Westphalen AC, Jung AJ, Noworolski SM, Simko JP, Kurhanewizc J, et al. Role of endorectal and MR imaging and MR spectroscopy imaging in defining treatable intraprostatic tumor foci in prostate cancer: quantitative analysis of imaging contour compared to whole-mount histopathology. Radiother Oncol (2014) 110:303-8. doi:10.1016/j.radonc.2013.12.003

64. Mena E, Turkbey B, Mani H, Adler H, Valera VA, Bernado M, et al. 11C-Acetate PET-CT in localized prostate cancer: a study with MRI and histopathologic correlation. J Nucl Med (2012) 53:538-45. doi:10.2967/jnumed. 111.096032

65. Onal C, Sonmez S, Erbay G, Guler OC, Arslan G. Simultaneous integrated boost to intraprostatic lesions using different energy levels of intensity-modulated radiotherapy and volumetric arc therapy. Br J Radiol (2014) 87:20130617. doi:10.1259/bjr.20130617

66. Fonteyne V, Villeirs G, Speelers B, de Neve W, de Wagter C, Lumen N, et al. Intensity-modulated radiotherapy as primary therapy for prostate cancer: report on acute toxicity after dose escalation with simultaneous integrated boost to the prostate. Int J Radiat Oncol Biol Phys (2008) 72:799-807. doi:10.1016/j.ijrobp.2008.01.040

67. Kim DW, Cho LC, Straka C, Christie A, Lotan Y, Pistenmaa D, et al. Predictors of rectal tolerance observed in a dose-escalated phase 1-2 trial of stereotactic body radiotherapy for prostate cancer. Int J Radiat Oncol Biol Phys (2014) 89:509-17. doi:10.1016/j.ijrobp.2014.03.012

Conflict of Interest Statement: The authors declare that the research was conducted in the absence of any commercial or financial relationships that could be construed as a potential conflict of interest.

Received: 01 August 2014; accepted: 15 January 2015; published online: 02 February 2015.

Citation: Nguyen NP, Davis R, Bose SR, Dutta S, Vinh-Hung V, Chi A, Godinez J, Desai A, Woods W, Altdorfer G, D'Andrea M, Karlsson U, Vo RA, Sroka T and the International Geriatric Radiotherapy Group (2015) Potential applications of imageguided radiotherapy for radiation dose escalation in patients with early stage high-risk prostate cancer. Front. Oncol. 5:18. doi: 10.3389/fonc.2015.00018

This article was submitted to Radiation Oncology, a section of the journal Frontiers in Oncology.

Copyright (c) 2015 Nguyen, Davis, Bose, Dutta, Vinh-Hung, Chi, Godinez, Desai, Woods, Altdorfer, D'Andrea, Karlsson, Vo, Sroka and the International Geriatric Radiotherapy Group. This is an open-access article distributed under the terms of the Creative Commons Attribution License (CC BY). The use, distribution or reproduction in other forums is permitted, provided the original author(s) or licensor are credited and that the original publication in this journal is cited, in accordance with accepted academic practice. No use, distribution or reproduction is permitted which does not comply with these terms. 